\title{
Research on Developing Dynamic Website for Benishangul Gumuz Regional State of Educational Bureau
}

\author{
Wakjira Mulugeta Asefaw and A. P. Hambisa Mitiku
}

\begin{abstract}
This research project was done by Assosa University College of Computing And Informatics. Developing Dynamic Website for Benishangul Gumuz Regional State of Educational Bureau, provides a simple and efficient way of facilitating education service. Since the redundancy and collection of relevant malfunctioned material information can be very time-consuming, it is difficult to achieve this objective using manual systems. All these challenges had been minimized by automating the manual system. This document contains the introduction, methodology that uses tools like Notepad++,HTML, wampserver and MYSQL, data sources like site observation, interview and document analysis, and for design methodology we use object-oriented. For analysis model we use sequence and activity diagram. For system design we include state diagram and use case diagram. To develop the real website, designs had been made that covers the website architecture, user interfaces and database designs.
\end{abstract}

Keywords - Benishangul Gumuz, client, dynamic Website, Educational Bureau Website, webserver.

\section{INTRODUCTION}

One of the pillar forces that accelerate socio-economic, social and political progress is called education. Education plays an important role by cultivating technical talents and improving human capital for the development of the country, creating suitable conditions for the development process, and helping to promote technological change [1].

The world is static changing in every aspect of life. Changes in a country's education system and global needs require the development of their respective professionals. With the rapid development of today's world, teachers, like most other professional groups, must know that their initial training is not suitable for their lives; they need to change and improve their knowledge and techniques throughout their lives [1].

This website enables the user to save many problems. Benishangul gumuz regional state educational bureau website had been connected with the internet in order to provide services to the user and to disseminate information across the world and exchange information cooperatively with related sites and other educational bureau institution.

\section{BACKGROUND}

The BenishangulGumuz Regional State is one of the nine federal regional states of Ethiopia. The region is bordered with republic of Sudan and three regional states such as with

Submitted on August 26, 2021

Published on September 17, 2021.

Wakjira Mulugeta Asefaw, Xidian University, Xian, China.
Amara to north and north east; with Gambella regional state to south; with Oromia regional state to east and south east directions. It has an area of 50,381 square kilometers [2].

Government: The head of BenishangulGumuz Regional State (BGRS) is the president who is elected by the council of the region. The Region is divided in to three administrative Zones and one special Woreda/District based on ethnicity, language and geographical location. These include Asossa zone, Kamashe zone, and Metkel zone and mao-komo special woreda/district. Flagas it is coded in the regional constitution, the regional state flag consists of Black at the top, Yellow at the middle, Green at the bottom and has a triangular Red which intersects the above three colours at the first side of the flag [2].

Capital: The capital city of BenishangulGumuz Regional State (BGRS) is Asossa which is found the north western part of Ethiopia located at about 675 kilometers west of Addis Ababa. According to the 2007 national census result by the Central Statistical Agency (CSA), the projected total population of the region is estimated to 670,847 in 2008 and the annual growth rate is 2.54 . The region has sparsely populated settlement pattern 13.3 per a kilometer square [2].

The BenishangulGumuz Region state educational bureau is not one of the regional institution established independently rather it is organized for the purpose of beating the mission of the organization associating with other sectors. It was established in 1986 E.C [2]. This bureau is dealing with a lot of work departments having connection with the Ethiopian federal ministry of educational institution to expand educated person in urban and rural area.

\section{Statement OF THE PROBlem}

Benishangul Gumuz regional state educational bureau website was suffering from numerous problems due to its manual nature of recording and reporting: difficulty of accessing record data from the database since the system was manual, time wastage for searching even a single data, problem of updating data, tedious and complex data manipulating when the numbers of users increases and difficult to manage.

\section{OBJECTIVE OF THE STUDY}

\section{A. General Objective}

The overall goal of this research project is develop a dynamic website for the State Education Bureau of Benishangul Gumuz Region.

(e-mail: wakjira@stu.xidian.edu.cn/wakm999@gmail.com)

A. P. Hambisa Mitiku, Jima University, Jima, Ethiopia.

(e-mail: hambisamitiku@gmail.com). 


\section{B. Specific Objective}

Specifically the project attempted to achieve the following objectives:

$\checkmark$ To analyze and specify the requirement of the system.

$\checkmark$ To identify and gather requirements from existing systems.

$\checkmark$ To design a way to solve the problem or to address the requirement that was specified in the analysis phase of the new system for $\mathrm{B} / \mathrm{G}$ regional state educational bureau.

$\checkmark$ To implement the new system or to change the design into real resolution that can lead to the final solution of the problem.

$\checkmark$ To test the system using various testing methodology to been sure the system was implemented with all functionalities.

$\checkmark$ To deploy the system in the working environment for Benishangul Gumuz regional state educational bureau.

\section{SIGNIFICANCE OF THE STUDY}

The major significance of this project for the Benishangul Gumuz regional state educational bureau was to facilitate their tasks in several ways like: To replace the current system (manual system) with a flexible, systematic and more reliable record management system. The new website was using computer to manage the record and access data from anywhere. It was more efficient and effective than manual system which was burden the staff in the working area. To easily manage educational information related activities. To develop more secured website for educational information system.

\section{BENEFICIARIES OF THE STUDY}

The beneficiaries of the website were:

$\checkmark$ Job seekers: the job seekers can access information easily and timely from the website.

$\checkmark$ Employees and other administrative officials: they can access the website and related information easily.

$\checkmark$ Benishangul Gumuz Regional State Educational Bureau: the educational bureau and regional state gets better audience can increase the number of educated person on the region.

$\checkmark$ Students: the students from anywhere can access information about the region relating with educational aspects.

$\checkmark$ Teachers: they get job opportunity from educational bureau.

\section{SCOPE OF THE STUDY}

The scope of this project was to develop and implement website. Regarding to the scope of project was limited in promotion and advertisement of educational bureau sector.

There are some activities that the system could perform, these are:

$\checkmark$ Post up-to-date and recent news;

$\checkmark$ Release news and vacancy;

$\checkmark$ Release bids and policies; $\checkmark$ Release education system and statistics;

$\checkmark$ Receive and feedback contact message;

$\checkmark$ Release annual, half year and monthly report.

\section{FEASIBILITY STUDY}

The objective was determined whether or not the new website was feasible the following feasibility study had been taken in to consideration for this project.

\section{A. Technical Feasibility}

The technical resources needed to develop, install and to operate had been done by the system developer using PHP plate form-,HTML,MYSQL,DB, window7operating system. So, the new website had been technical feasible.

\section{B. Economic Feasibility}

The system had been economically feasible as a result of it reduces the time needed to perform certain actions such as registration process, man power, paper and which they are using for manual work based. Accordingly, economic feasibility can be intangible and tangible benefits. Tangible and intangible benefit specifies the benefits and costs associated with the project.

The Tangible benefits of the system had been including:

- Material cost reduction;

- Save time and make comfortable working environment for the users;

- Increased service and reduced extra resource, reduced the number of manpower;

- And reduced processing error and decrease response time.

The Intangible benefit may also include:

- Improved customer good will;

- Improved employee morale;

- Better services to community increase management flexibility;

- Increase information accuracy and increase information processing efficiency. So, the project was economically feasible.

\section{Operational Feasibility}

Sure that the new website could been easily operated and solve the existing problem and accessed by the user anywhere. Once the website was deployed it can operate on any of the operating systems without any mal functionalities. The users once had been trained how to use the software they can easily use it without any doubt because of its simplicity. Since the new website uses very friendly application and it had its own simple procedures to do with, assume that they will find it easy in their daily activity. for this a reason, the website was supported by the user the website had not been degraded or declined if some serious problems had been occurred ,the website had been easily maintained by the developer. Therefore, the website had been designed to been operationally feasible.

\section{Political Feasibility}

The new website had been behaviorally feasible. It cannot cause any harm in the environments. The project had been beneficial because it satisfies the objectives of the customer or users. The website had been developed user friendly and 
improves the working environment .So the new website was free from any political and environments difficult.

\section{LITERATURE REVIEW}

Nowadays communication between end users and institutions is available via websites. The main goal of website is to spread information.In the development of website ,usability,SEO(Search Engine Optimization) and accessibility are very important [3]. Dynamic website can simply provide information to the users.Using Firefox browser or Google Chrome are must important to use the web [4]. In the development of dynamic website design models and diagrams, the flow of information is gradually displayed.During In [5] develop usable cross-cultural websites using model.The web page that is generated by a server -side program or script is called dynamic web page[6].Most popular organizations use dynamic websites instead of static websites because dynamic websites have databases connected to servers.In [7] the website is a dynamic and has a permanent update frequency.In dynamic website the content and design live in different way [8]. Website is vary rely on the context of the website [9]. Recently, most government organizations use websites to publish information announcements, and recruit job vacancies.

In [10] to build the digital capital of real estate websites. The old method of developing website is not enough to satisfy the end user [11]. The dynamic website is composed of templates, scripts, etc. This world can be connected through internet [12]. It can also possible to generate web pages in real time.In [13] website are the major world communication channel. Developing website for educational organization is very important [14]. One of the most important things in the website are establish web server and deploy the web [15]. Website is easy to distribute the information to the society and organization [16]. Dynamic website display information for the clients.Huge website need more automatic method and content translations [17]. Government website are primary website but education, health,tourism, university and eBay are secondary websites [18]. The development of internet is very important for various people [19]. One of the most ways to share information to usersis called website [20]. Organizational website include huge number of electronic data: photo, video files; code files; text, graphic and etc. [21]. Websites can be accessed on the Internet using the Internet and published on web pages [22]. There are various kind of websites such as private, governmental, commercial and non -governmental websites [23]. Non-governmental websites are volunteer organization [24].

There are two kind of websites:static and dynamic website.Static website is easiest to create a website and display information to users. There is no need to create a database architecture and programming in a static website. It can be built using HTML and display information to a web server. This kind of website structure is fixed, and more web pages are constructed through templates [25]. However, dynamic websites is different from static website because it can access information from the database. In order to write the code the programmers used PHP or ASP. Most of the large organizanization used dynamic website to build their website [26].
Therefore, the B / G Education Bureau is affiliated with the Benishangul-Gumuz Regional State (BGRS), but it is not an existing developed website, so this research project aims to develop the college's own website to fulfill its purpose and functions, to disseminate information easily.And in addition, this research project can provide a static and dynamic website.

\section{Project Design And Methodology}

\section{A. Study Area}

Benishangul Gumuz Regional State is one of the nine federal regional states of Ethiopia [27]. It is located in the north western parts of Ethiopia. The region is bordered with republic of Sudan and three regional states such as with Amhara to north and north east; with Gambella regional state to south; with Oromia regional state to east and south east directions [27].

According to the 2008 national census result by the Central Statistical Agency, It has an area of 50,381 square kilometres, the projected total population of the region is estimated to 670,847 in 2009 and the annual growth rate is 2.54 [2]. The capital city of Benishangul Gumuz Regional State is Asossa which is found the north western part of Ethiopia located at about 675 kilometres west of Addis Ababa [2].

\section{B. Source of Data}

The data was obtained from both primary and secondary source of data:

\section{$\checkmark$ Primary source of data}

The primary source of data in the findings of the project in Benishangul Gumuz Regional state educational bureau was the employees' and administration director of Benishangul Gumuz Regional state educational bureau through interview.

$\checkmark$ Secondary source of data

Secondary data collected from various sources such as books, research papers, web-sites and other sources of data that are related to the study nearly educational website.

\section{Data Collection Technique}

Data collection technique is the technique of collecting or gathering data from the source of information such as persons, internet and by read related books with website. In order to achieve the objective of the new website first data gather is necessary to know the real fact of the current system. To collect information about the B/G Regional State Educational Bureau, the project team would use two type of data collection techniques. These are:

\section{$\checkmark$ Direct Observation}

Making direct observation and looking how the existing system operated in Benishangul Gumuz Regional state educational bureau and grinding the problem that is related to educational sector has been proceeded. At this theme particular deeds was gathered from the organization.

$\checkmark$ Interviews

Interviewing is very essential to collect huge amount of information. The team interested on individual interviewing. The team questioned the question to different people that concerned with educational development. 


\section{SySTEM ANALYSIS}

The team had collected the required data from staff workers using altered instruments and then analyzed the data and the whole system. Currently a well-organized educational institution must have a website in order to perform multiple functions. Such as disseminate relevant information to the user through online the use of the website. Through designing website which includes database drive websites and dynamic one. This website allows the administrator to add, delete, modify and search information on the database. And this website allows the users to search news and vacancy and use information and further this websiteand allows the users for online submit comment by filling up the appropriate comment form.

Generally the existing system environment of manual based methods in the sector takes a lot of efforts and human resources in case of distributing official papers associated with Ethiopian ministry of education.

The new system provides suitable way of accessing information about the regions quality of education for sustainable generation. Generally the new systems fix problems stated in the statement of the problem.

\section{A. Existing System Description}

The existing system works the jobs manually such as, manage the employer, prepare report assigning job for job seekers, manage conflict among the employers, provide materials to community, and disseminate information that related with education.

\section{B. Problem of the Existing System}

As the team tried to describe in part one the existing system had a number of problems since it is paper based (manual) system. Some of the problems include:

- Difficult to update record;

- Time consuming to the activity;

- Needs much man power;

- No validation.

\section{Strength and Weakness of the Existing System}

$\checkmark$ Strength

The ability to explain or advice the rule of educational bureau to whole employers before starting any activity. The whole employee is very cooperative for their duties performed even if bulky work. The existing system gives all the facilities that are provided by the educational bureau services.

$\checkmark$ Weakness

The main weaknesses of the existing system are the following:

- Report cannot be reach in a short period of time to the receiver.

- Any users cannot send comment to the sectors.

- Lose of available file from the file location.

\section{PROPOSED SYSTEM}

\section{A. Functional Requirement}

Functional requirement is the major functionality of the website that should be possessed. The new website had been able to keep all the important information saves safely in the database. The website is user friendly and easy to use. The efficiency has been improved for everyone involved by the automated website. Data storing has become easier. The new website has the following functional requirement.

- $\operatorname{login}$;

- insert necessary record into the appropriate place and time;

- delete unnecessary record;

- update record in the database;

- generate report;

- the website should store all the data related with all the tasks performed into a database.

\section{B. Non-functional Requirement}

Non-functional requirements are an additional feature of the website. The non-functional requirements of the new website had been the following.

- Error Handling: the website handled the errors in a very efficient manner. It has tolerated two wrong inputs and prompted to the users to correct their inputs. It gave notifications as and when required, guiding the users to properly utilize it.

- Security: the system is much secured, unauthorized user cannot access the system.

- Availability: The data in the system are available. Performance: The system provides fast access to the user according to their interest.

- Reliability: The system capable to perform a required function under stated conditions for a specified period of time.

- System modification: on every occasion modification necessary, the system supports such procedure.

- User friendlily: the website interface is interactive and easily understandable.

- Response time: throughout retrieving and, the system response time is short.

$\checkmark$ Business Rule

A business rule is effectively an operating principle or policy the system must satisfy. It often concerns to access control issues, and operating polices and principles of the new developing system. Therefore, the system has the following business rules.

$\checkmark$ Authorize to the system.

$\checkmark$ The system administrator should administer the system and stretch accesses (views).

$\checkmark$ Validate Information.

\section{REQUIREMENT SPECIFICATION}

This section describes the hardware components and software requirements required to run the system effectively and efficiently.

TABLE I: HARDWARE SPECIFICATION

\begin{tabular}{cl}
\multicolumn{2}{c}{ TABLE I: HARDWARE SPECIFICATION } \\
\hline Name & \multicolumn{1}{c}{ Description } \\
\hline Computer & $\begin{array}{l}\text { For documentation and implementation the project } \\
\text { It is a largest data storage device used to store and } \\
\text { transport fill. }\end{array}$ \\
Hard disk & $\begin{array}{l}\text { Is used to print the documentation of the project. } \\
\text { Is a small storage device used to transport file from } \\
\text { Flash }\end{array}$ \\
one computer to another. \\
Network cables & Use to connect computers to switch. \\
CD-RW & Used save our document to submit our project
\end{tabular}


TABLE II :SOFTWARE SPECIFICATION

\begin{tabular}{|c|c|c|}
\hline $\mathrm{NO}$ & Software tools & Applications of the tool \\
\hline 1 & Microsoft word 2010 & $\begin{array}{l}\text { Usedto write documentation of the } \\
\text { project }\end{array}$ \\
\hline 2 & $\begin{array}{l}\text { Microsoft power } \\
\text { point } 2010\end{array}$ & $\begin{array}{l}\text { Usedfor prepare powerpoint for } \\
\text { presentation }\end{array}$ \\
\hline 3 & Edraw max & $\begin{array}{l}\text { Is applicable fordesign different } \\
\text { diagram of the system }\end{array}$ \\
\hline 4 & Wampserver & $\begin{array}{l}\text { To implementation the code and to } \\
\text { design interface }\end{array}$ \\
\hline 6 & Browser & $\begin{array}{l}\text { Used to search different information } \\
\text { with internet. }\end{array}$ \\
\hline 7 & $\begin{array}{l}\text { MYSQL or SQL } \\
\text { server }\end{array}$ & $\begin{array}{l}\text { Used to store, retrieve, update different } \\
\text { information. }\end{array}$ \\
\hline 8 & HTML( language) & Used to create webpage \\
\hline 9 & PHP( language) & $\begin{array}{l}\text { Is intended to be a simple, modern, } \\
\text { general-purpose, object-oriented } \\
\text { programming language used to } \\
\text { implement the proposed system. }\end{array}$ \\
\hline
\end{tabular}

$\checkmark$ Other requirement

- Book: Used for reference purpose.

- Exercise book: Help to take notes when we refer more information related to the project.

- Paper: Used to take notes, establish/print documents

$\checkmark$ User Interface

The user interface of the system is the portion that the user directly interacts. The following activities are user interface of Benishangul Gumuz regional state educational bureau website.

TABLE III: USER INTERFACES AND THEIR IDENTIFICATION NAME

\begin{tabular}{cc}
\hline ID & User interface name \\
\hline 01 & Homepage \\
02 & About us \\
03 & News and vacancy \\
04 & Publication \\
05 & Bid \\
06 & Photo Gallery \\
07 & Comment(feedback) \\
08 & Contact us \\
09 & Statistics \\
10 & Policies \\
11 & Education system \\
12 & Login \\
14 & Report \\
\hline
\end{tabular}

\section{System DESIGN}

System design for the development of a website is important. In order to design, once project website developer use either structured or unstructured Modeling or Unified Modelling Language (UML). UML is easier to design once project. Since, UML include like use case diagram, activity diagram, state diagram, and sequential diagram; and it is possible to show the website what look like in easy way rather than system analysis and design. For this project, object oriented system analysis and design or UML had been used. So, the team developed well structure system both in physical interface and integrate link.

The object oriented software design methodology had been used to develop the new website. We have selected object oriented approach. This OOP is categorized in to three steps: object oriented analysis that arrange the object and create a relationship between them, object oriented design that design the implementation of the environment and object oriented implementation that operate the website using OOP.In this research project we will use PHP plate form,HTML and database is MYSQL.

\section{Use CASE Diagram}

Use Case represents interaction between a user (human or machine) and the website.

Use case components:

- Actor: It is a person who interact with the website.

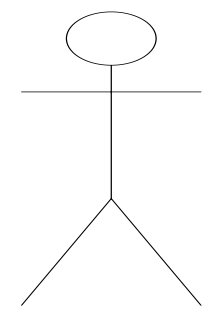

- Use case: It explain the step of actions that provide information to the actor and show as a horizontal ellipse.

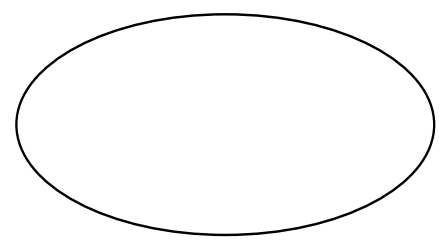

- System boundary: It show the scope of the website.

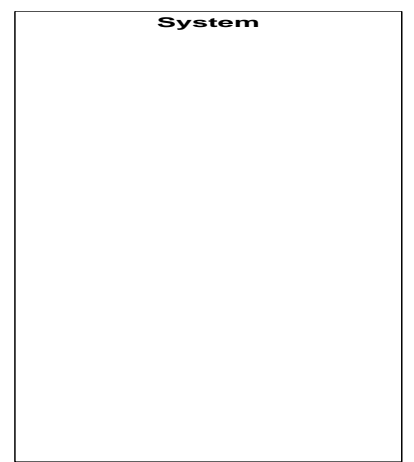

\section{A. Actor Identification}

In use cases, actors interact with the website to perform meaningful job, help them achieve their goals, and have the right to define their overall role in the website and the scope of their actions. Depending on the above explanation actors in this website are the following:

- Users: view Bid, news, vacancy, education system, policies, statistics, submit and view comment and send message and search news and vacancy..

- Administrator: Add news and vacancy, bids, education system, policies, statistics, Update, delete record ,create account, view message and manages the overall website

\section{B. Use Case Identification}

Each Use Case describes the functionality to be built in the new website, which can include another Use Case's functionality or extend another Use Case with its own behavior. Each use case describes the functionality to be built in the new website, it can include the functionality of another 
use case, or use its own behavior to extend another use case.The most important and basic use cases of this website are the following:

- login;

- create account;

- send message;

- view message;

- submit comment;

- view comment;

- add publication;

- publication;

- add news and vacancy;

- view news and vacancy;

- update record;

- delete record;

- post statistics;

- view statistics;

- post policies;

- view policies;

- post education system;

- view education system;

- generate report;

- view report;

- add bid(business initiates direction);

- view bid(business initiates direction);

- search news and vacancy;

- logout.

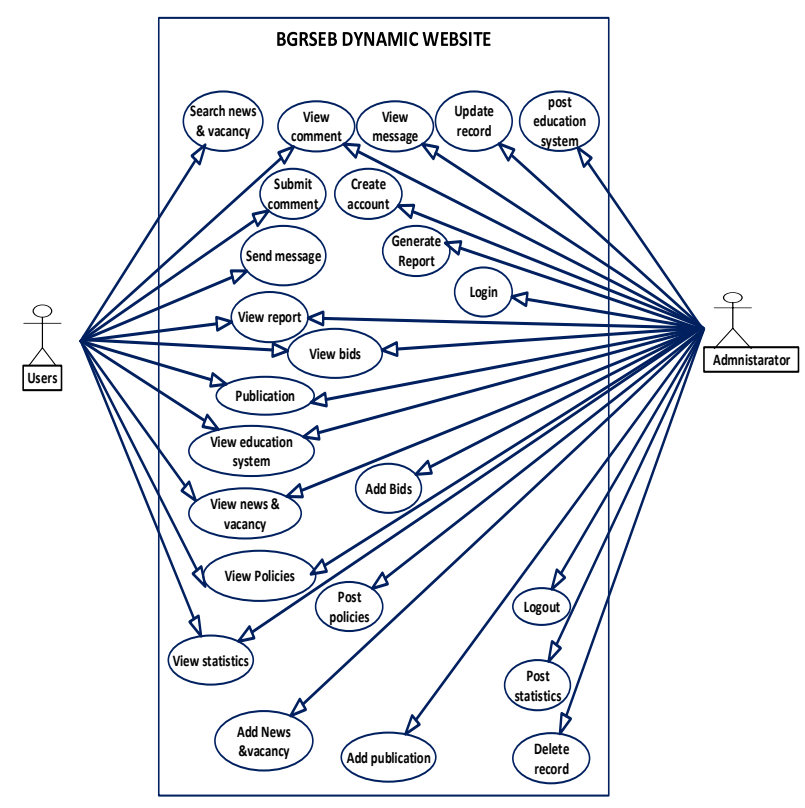

Fig. 1. Use case diagram for the proposed website.

TABLE IV: USE CASE LIST NAME AND THEIR IDENTIFICATION.

\begin{tabular}{cc} 
& USE CASE LIST \\
\hline ID & Use case actor \\
\hline uc01 & Login \\
uc02 & Create account \\
uc03 & Add management area(add tasks) \\
uc04 & Update record \\
uc05 & Delete record \\
uc06 & Search news and vacancy \\
uc07 & Submit comment \\
uc08 & View comment \\
uc09 & send message \\
uc010 & View message \\
uc011 & Add publication \\
\hline
\end{tabular}

Use case description

1. Name: Login.

ID: UC01.

Description: login to the website.

Actors: Administrator.

Precondition: There must be a login form.

Normal Course of action:

- Administrator need to enter the website.

- Website displays login form.

- Administrator enters user email \& password and click login button.

- The website checks the user email \& password and approved.

- The website display appropriate page for Administrator.

- Use case ends.

Alternative Course: Login failed.

- The website checks the invalidity of information(user email and password).

- The website informs the user email and password entered is invalid and informs to reenter.

- Use case ends.

Post condition: existing login.

2. Name: Create account

ID: UC02.

Description: To signup Form.

Actors: Administrator.

Precondition: There must be a signup form.

Normal Course of action:

- Administrator need to enter the website.

- Website displays signup form.

- Administrator enters the required field and click signup button.

- The website checks the form and approved.

- The website display appropriate form for Administrator.

- Use case ends.

Alternative Course: signup failed.

- The website checks the invalidity of information.

- The website informs the required field signup is invalid and informs to signup.

- Use case ends.

Post condition: existing Signup form

3. Name: Add management area (Add task).

ID: UC03.

Description: The Administrator add tasks such as Add BGRS educational bureau contact address, Add news vacancy, Add statistics,policies,education system,bid, Add Homepage posts, Add Read Full Message, and Full Message post; which the user or the visitor views on the Homepage of the website.

Actor: Administrator.

Precondition: Administrator should be fulfill the requirement.

Basic course of action:

- Administrator to open the web page and the registration form.

- Administrator to fill the form.

- The website to check the data is valid or not.

- To display the success message.

Alternate course of action:

- The users can't get the application form.

- The users see what the administrator add. 
- Use case end.

4. Name: -update record.

ID: UC04.

Description: update record.

Actor: administrator

Precondition: administrator have existing file.

Post condition: Administrator that record.

Basic course action.

- Only the administrator is updating this record.

- The website update administrator record

- Alternative course of actions: none.

- Use case end.

5. Name: Delete record.

ID:UC05.

Description: Delete record.

Actor: Administrator.

Precondition: administrator have existing file.

Post condition: Administrator deletes existing record.

- Administrator select record what they delete.

- Administrator clicks delete user button.

- Then clicks ok button.

- "User successfully deleted!" message displayed.

- Use case end.

Alternative Course:

- Insert data is not match! Error message.

Post condition: record deleted from the website.

- none.

- Use case: end.

6. Name: Search news and vacancy

ID: UC06.

Actor: Users.

Description: used to search news and vacancy need.

Post condition: view news and vacancy.

Basic Course of Action.

- Users search the website.

- Users navigates and select search menu item.

- Website displays search form.

- User inputs search key.

- User click search button.

- website search the input information.

- Website display the information.

Alternate course of action:

A. If they do not found the information.

The website display "not found" message.

7. Name: Submit Comment.

ID: UC07.

Actors: Users.

Description: Users can give comment.

Precondition: The users have valid user name.

Post condition: The users send comment to the website.

Basic Course of Action.

- The users initiate to give comment.

- The users fill all the required fields.

- The website displays the comment form.

- The website validates the entered information.

- The website display as your comments has been sent.

- Use case ends.

Alternate course of action: none.

8. Name: view Comment.

ID: UC08.

Actors: Users and administrator.
Description: Users and administrator can see the comments that are submitted from the user.

Precondition: The must have comment form.

Post condition: The users and Administrator views the submitted comments.

Basic Course of Action.

- Administrator click on home page.

- The users and Administrator starts to view the comments.

- The website reorders the comments according to the time of delivery.

- Use case ends.

Alternate course of action: none.

9. Name: send message.

ID: UC09.

Actors: Users.

Description: Users can sent message for Administrator.

Precondition: The Users must have a fill the form to sent message for administrator.

Post condition: The Administrator views the submitted message.

Basic Course of Action.

- Users click on message button.

- Users starts to fill the form.

- Users click on sent button.

- Use case ends.

Alternate course of action: none.

10. Name: view Message.

ID: UC10.

Actors: Administrator.

Description: Administrator can see the message that is submitted from the user.

Precondition: The Administrator click on view contact message.

Post condition: The Administrator views the submitted message.

Basic Course of Action.

- The Administrator starts to view the messages.

- The website reorders the message according to the time of delivery.

- Use case ends.

Alternate course of action: none.

11. Name: Add publication.

ID: UC11.

Actors: Administrator.

Description: The Administrator upload publication such as Magazines, files, and written, documents which the user or the visitor can download from the website.

Precondition: From the homepage, the Administrator clicks on "Add publication menu items".

Post condition: the Administrator add thus publication to the data base and any one see and download them dynamically from the data base.

Basic Course of Action.

- The Administrator needs to add publications which are displays on Homepage.

- The Administrator click on "Add publication" from the Administrators homepage.

- The system displays the Add publication and by fill the requirement he/she can perform and deal with the task.

- Use case ends. 


\section{Sequence Diagram Modeling}

Sequence diagrams are usually created to show the flow of messages between objects and actors in a website. The sequence diagram answers questions about how the website works. Once we have created the sequence diagram, we need to determine which roles and objects to put on it. One method is to drag all the actors involved in the use case to the sequence diagram, and then traverse the functions, adding objects as needed to facilitate the functions.

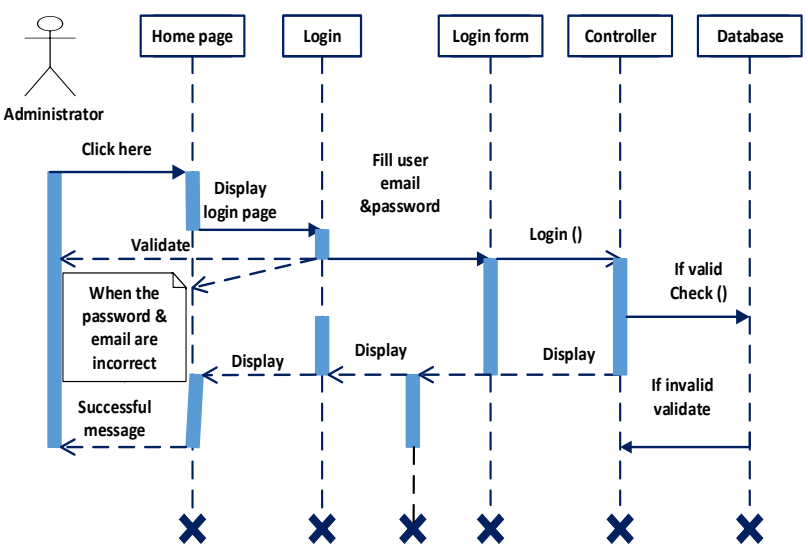

Fig. 2. Sequence diagram for login.

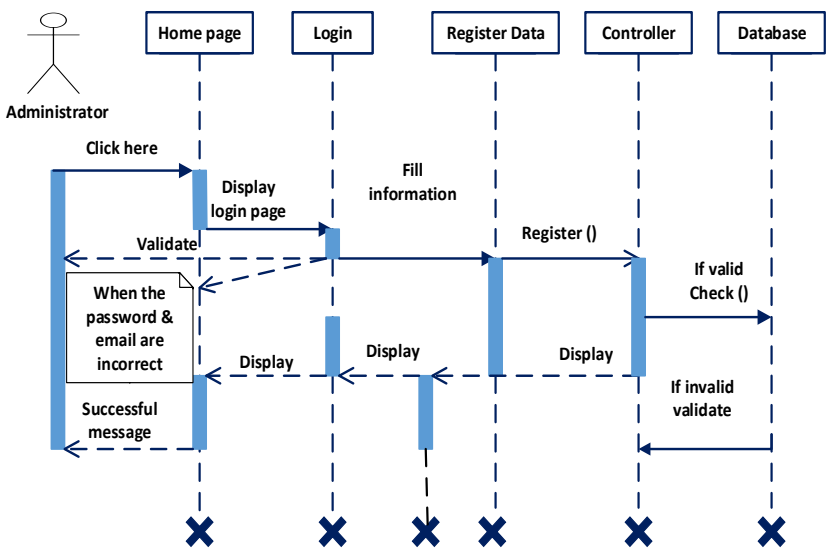

Fig. 3. Sequence diagram for Register data.

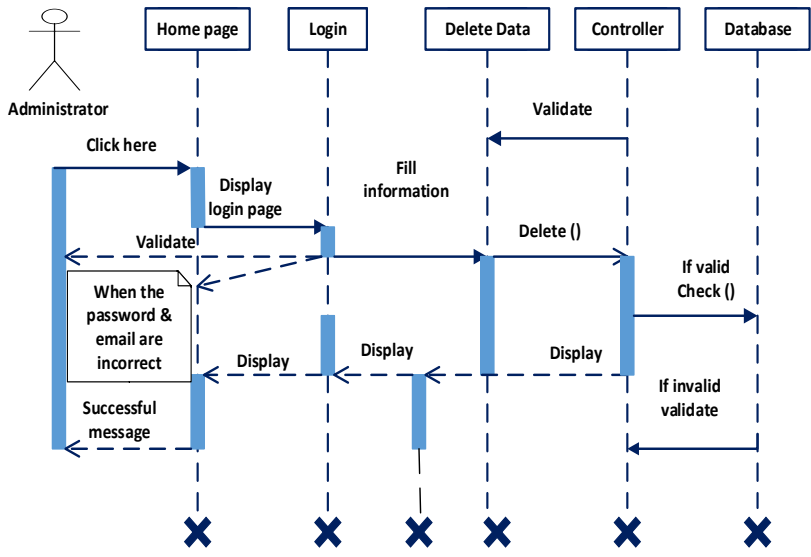

Fig. 4. Sequence diagram for Delete data.

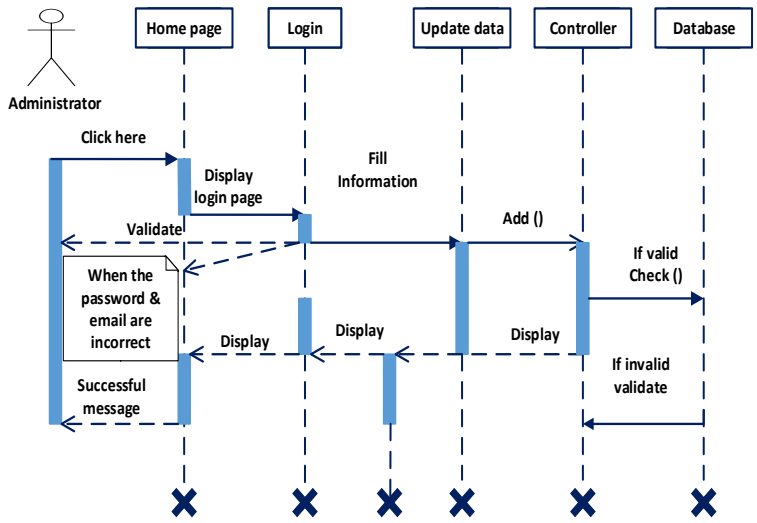

Fig. 5. Sequence diagram for Update data.

\section{State Chart Diagram}

The state diagram is a state machine view that models the behavior of state changes. The state diagram shows the various states that the object goes through. The common model elements included in the state diagram are:

-state;

- start and end states;

- transition.

State represents a condition in the life cycle of an object, during which it meets a certain condition or waits for an event. The start and end states indicate the beginning or end of a process.

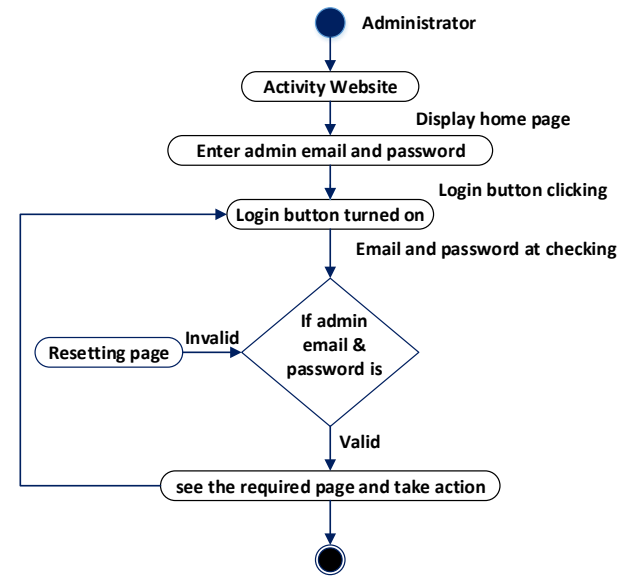

Fig. 6. State chart diagram for login.

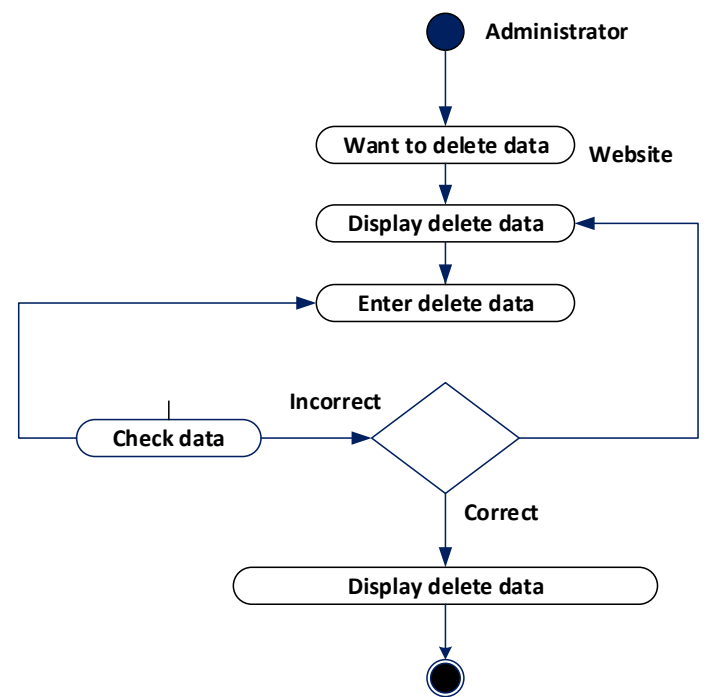

Fig. 7. State chart diagram for Delete. 


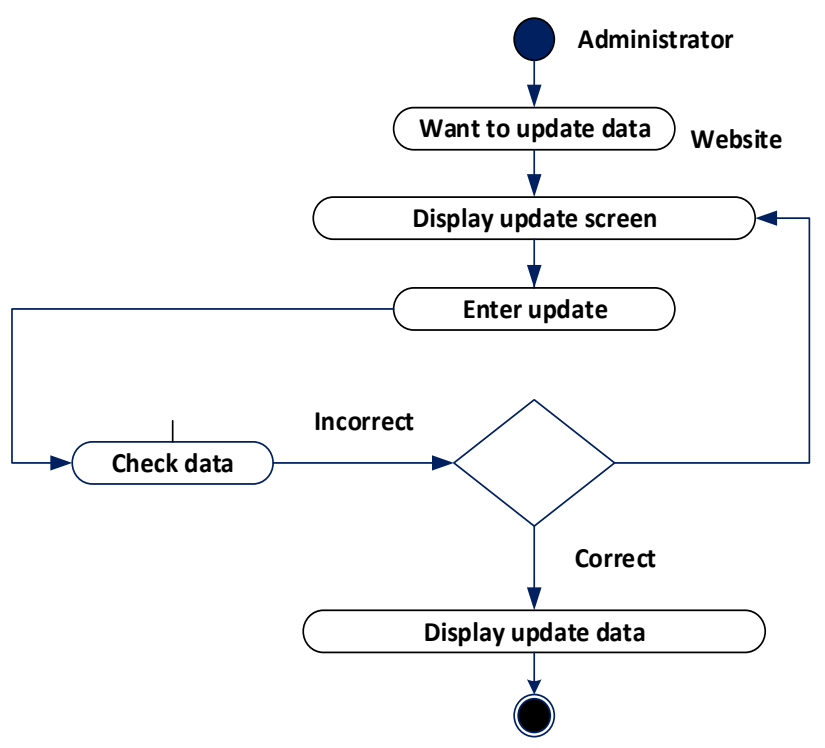

Fig. 8. State chart diagram for Update.

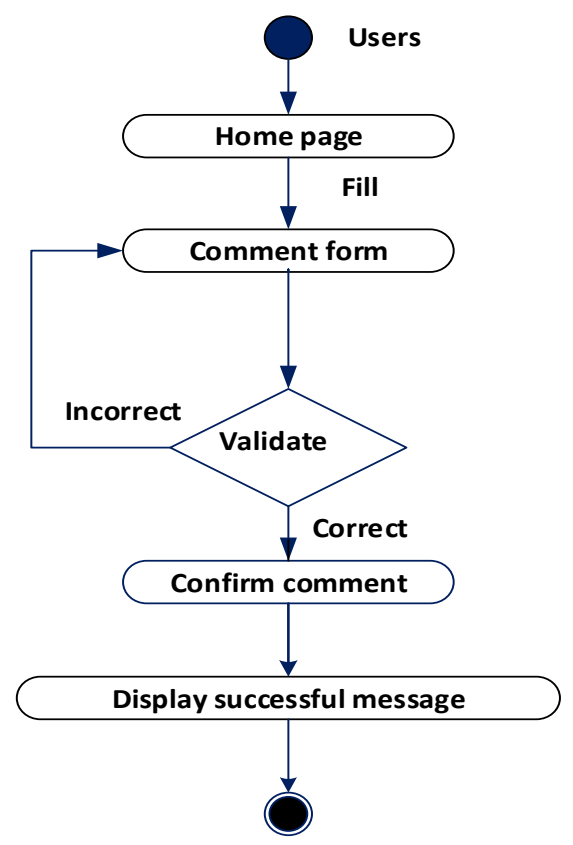

Fig. 9. State chart diagram for Comment.

\section{ACTIVITY DIAGRAM}

Activity diagram is another essential diagram in UML that describes the dynamic aspects of a website. An activity diagram is basically a flowchart used to represent the flow from one activity to another activity. This activity can be explained as an action on the website. Therefore, the flow of control is drawn from one operation to another. The purpose of the activity diagram can be described as:

- Draw the activity flow of the website.

- Describe the sequence of the action from one activity to another.

- Describe the parallel, branching, and concurrent processes of the website.

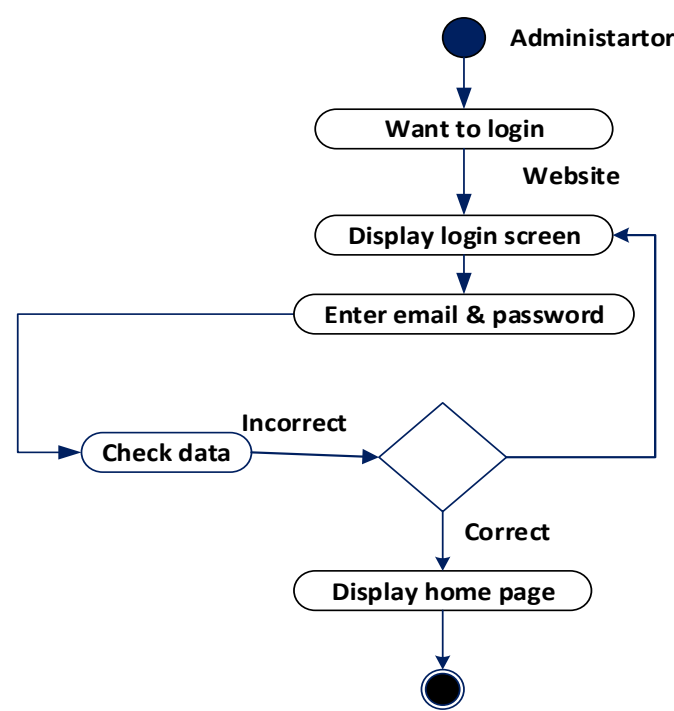

Fig. 10. Activity diagram for login.

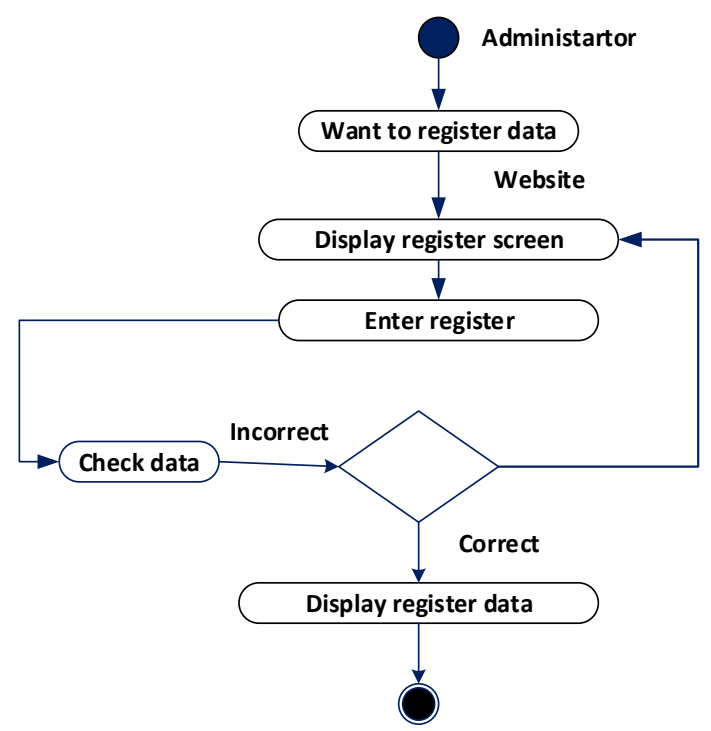

Fig. 11. Activity diagram for register data.

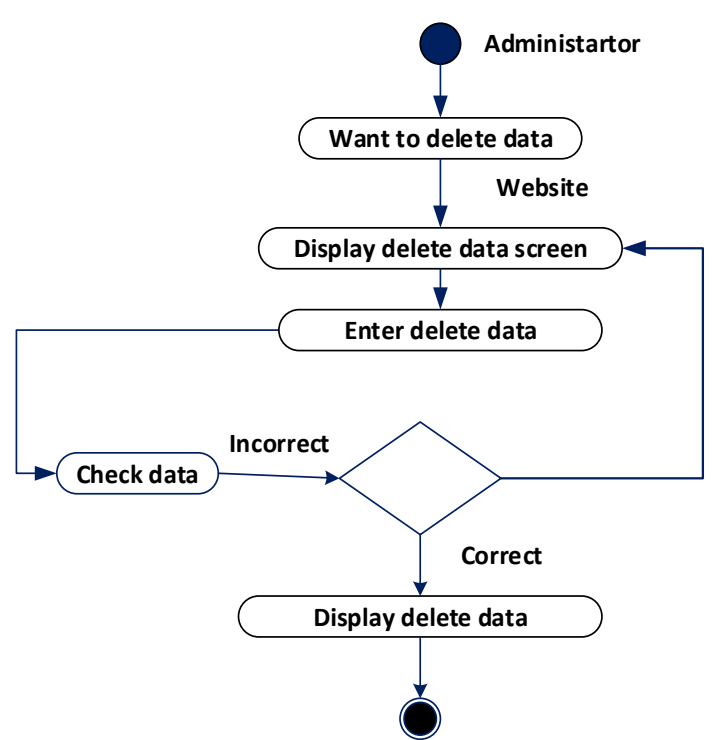

Fig. 12. Activity diagram for delete data. 


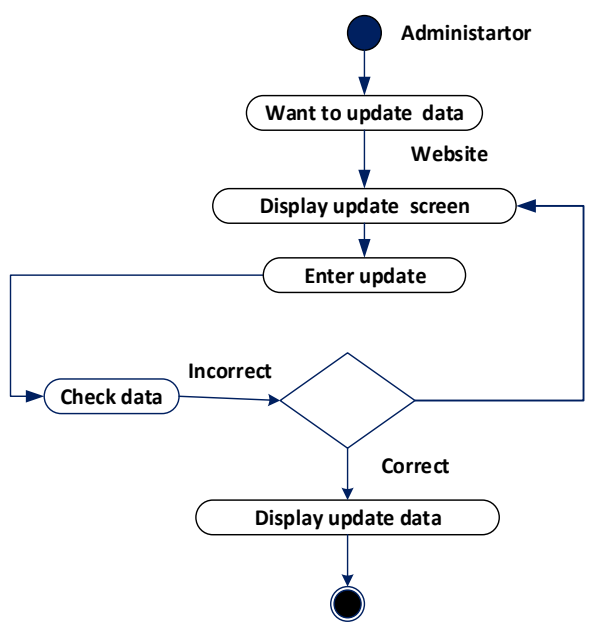

Fig. 13. Activity diagram for Update data.

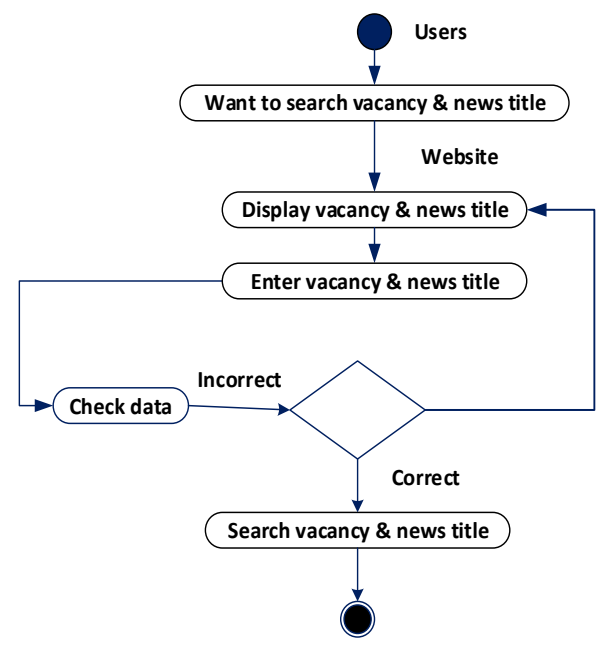

\section{DEPLOYMENT DiagRAM}

This diagram show that the configuration process of runtime and components of the software.

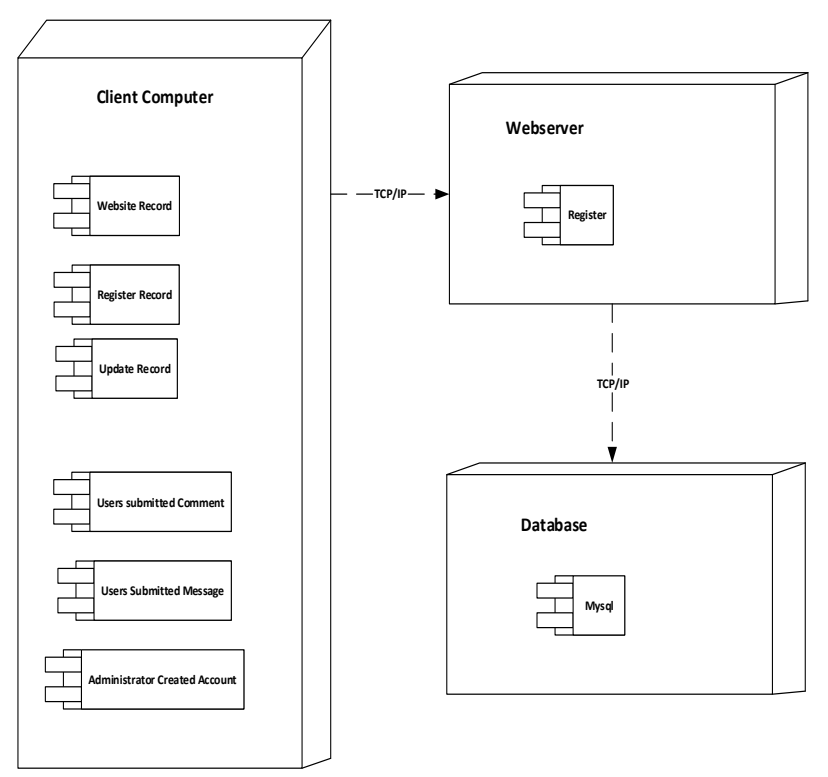

Fig. 15. Deployment diagram.

\section{USER INTERFACE PROTOTYPE}

User interface prototyping is an iterative development method in which users actively participate in the modeling of the website UI.

Fig. 14. Activity diagram for Search.

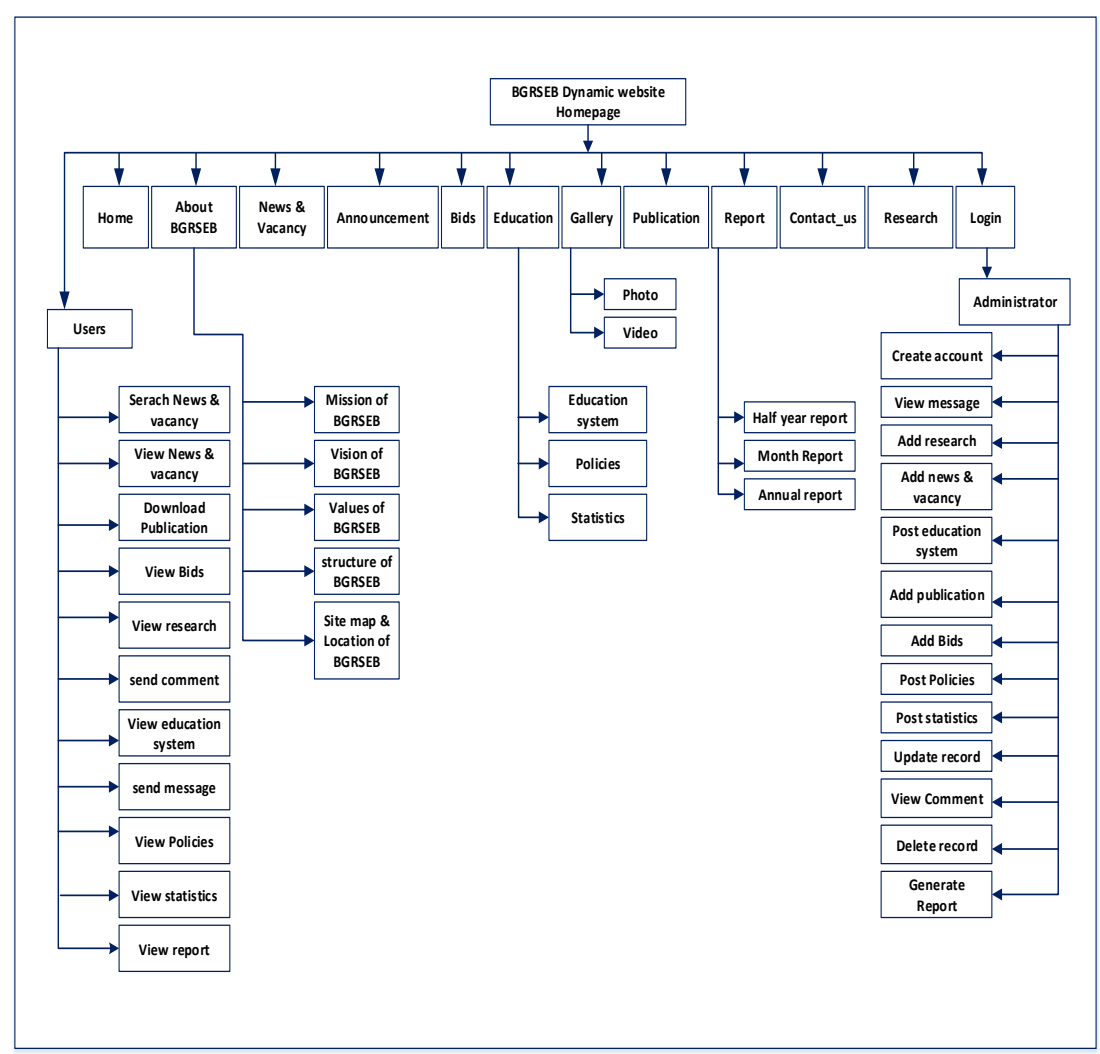

Fig. 16. User interface prototype. 


\section{EXPERIMENTATION}

Experimentation supports projects that involve building and evaluating information processing and website development. These are goal-oriented projects usually under taken by designers, builders and users, Emphasis on building the website and on project experiments involving the website that address significant and timely proposal questions. The development dynamic website of regional state educational bureau about BenishangulGumuz Educational Bureau must itself represent a major intellectual that had advance the understanding of information processing systems architecture. The website prototypes being built should be suitable for exploring application and performance issues.

\section{IMPLEMENTATION}

The team implements the project window based web application use PHP: used for server side scripting language, HTML: used for creating WebPages, wamp server:also used for server side scripting languages,Mysql server DB: used to create database and tables to store information, Java script: used for client side scripting languages and form validation, Flash: used to make animating video and image as well as the texts.In order to make attractive to the user and installing the packages in administrator computer at the centre and make functional to solve the problems that is stated in the statements of the problem.

\section{USER INTERFACE DESIGN}

User interface is the external part of the website which is used to access and interact with the website easily.

\begin{tabular}{cc}
\multicolumn{2}{c}{ TABLE V: HOME PAGE USER INTERFACE } \\
\hline User interface name & BGRSEB website Home page \\
\hline $\begin{array}{c}\text { User interface description } \\
\text { Relationship }\end{array}$ & It serve as index to user home \\
Search form
\end{tabular}

Steps to followed to use the interface:

1. Type BGRSEB website URL in address bar of web browser.

2. The page will be displayed because it is default page.

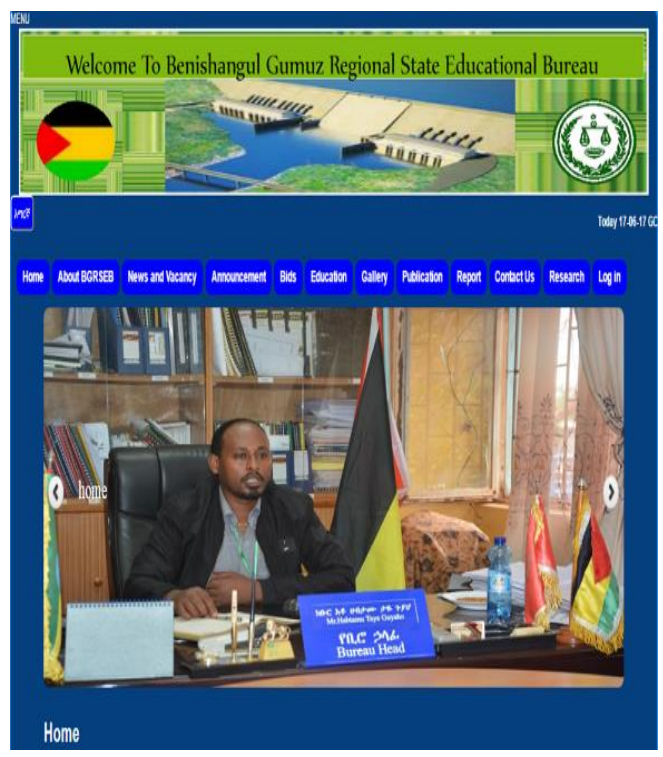

Fig. 17. Home page user interface.
TABLE VI: LOGIN PAGE USER INTERFACE

\begin{tabular}{cc}
\hline User interface name & Login page \\
\hline User interface identifier & Administrator log in by this page. \\
\hline
\end{tabular}

Steps to followed to use this interface:

1. Type your user email and password.

2. Click login.

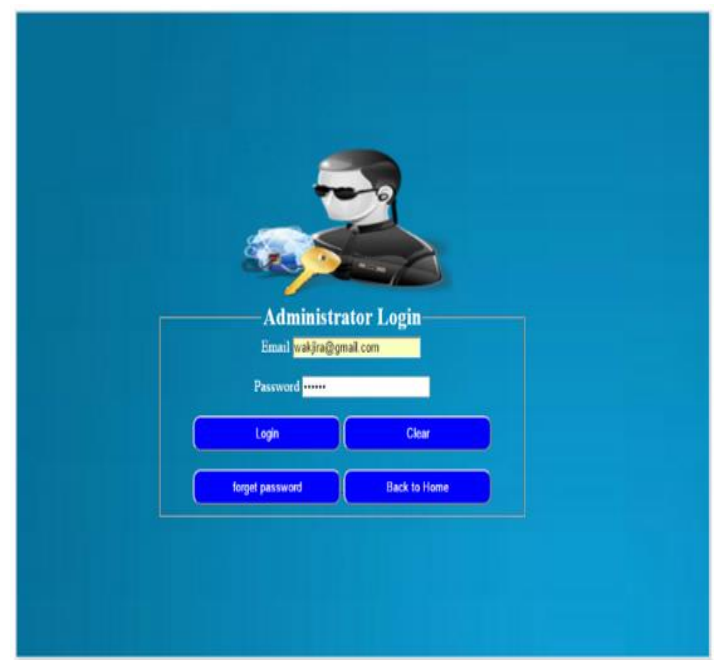

Fig. 18. Login page user interface.

TABLE VII: CREATE ACCOUNT USER INTERFACE

\begin{tabular}{cc}
\hline User interface name & Create account page \\
\hline $\begin{array}{c}\text { User interface identifier } \\
\text { User interface } \\
\text { description }\end{array}$ & Administrator \\
& Administrator has a responsibility to create \\
& new account. \\
\hline
\end{tabular}

Steps to followed to use this interface:

1. Administrator click manage account.

2. Form will be displayed.

3. Fill it properly.

4. Create.

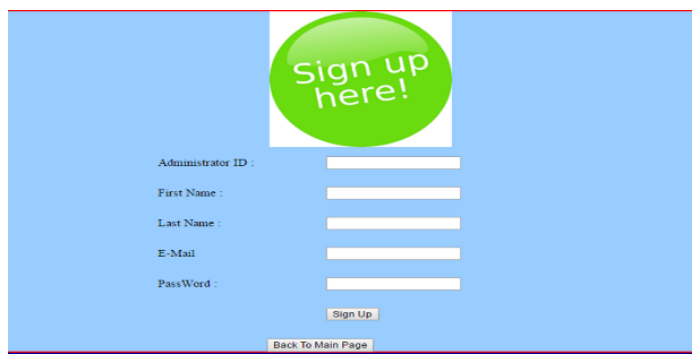

Fig. 19. Create account user interface.

TABLE VIII: REGISTER, UPDATE, AND DELETE RECORD INFORMATION USER INTERFACE

\begin{tabular}{cc}
\hline User interface name & Submit, update, and delete record information page \\
\hline $\begin{array}{c}\text { User interface } \\
\text { identifier } \\
\begin{array}{c}\text { User interface } \\
\text { description }\end{array}\end{array}$ & Administrator \\
& Administrator Register, update, and delete data in the \\
website.
\end{tabular}

Steps to followed to use this interface:

1. Administrator select on title.

2. Click on news or vacancy.

3. Register form had been displayed.

4. Record successfully.

5. Update and delete form display.

6. Click update or delete button. 


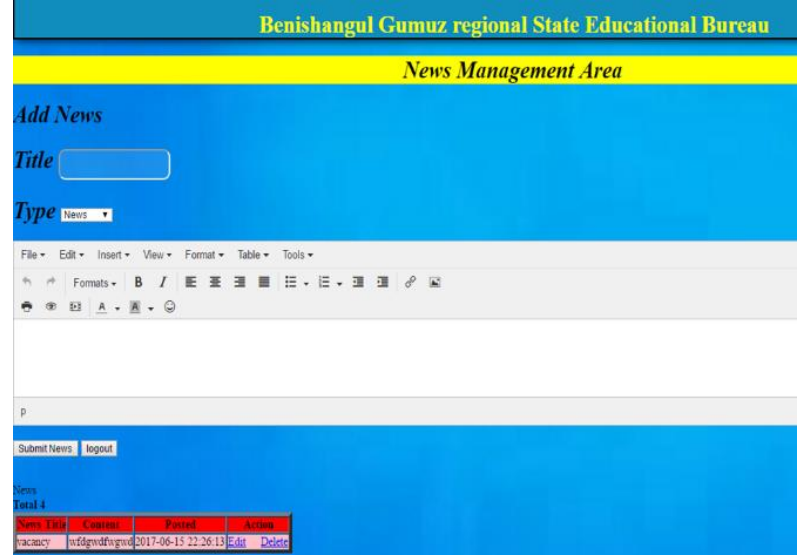

Fig. 20. Register user interface.

\section{TESTING}

In order to make sure system is functional testing is made at deferent stages of the system. Any new system needs to be tested before being introduced. The coding has started, and the testing process can begin and proceed in parallel. Because the generation of each program module can be tested individually, not as part of a larger program and then as part of a larger system. Test the relationship and differences between existing subsystems and new system development. The following are the different test steps:

$\checkmark$ First, perform a normal data test on the system to see if it can work normally.

$\checkmark$ Second, the system uses data containing known errors to test and try to make it fail.

$\checkmark$ Third, the system is tested with a very large amount of data to see how it responds.

Testing is a method to check the project is acceptable or not and it helps to see the error of the project one by one. In this method when the researcher checks the project and it avoids if the errors are occurred and also corrects the error. This is very important method because after finishing the whole project; the users are practice the project without any mistake. To test system the investigator use the following most common testing methods. So researchers check the system every time when at the time of doing the project.

\section{A. Unit Testing}

This research project did by examining each unit of the system. Example for Administrator login.

Description: when the Administrator enter incorrect user email and password there is the message "Incorrect user name or password."Message is display.

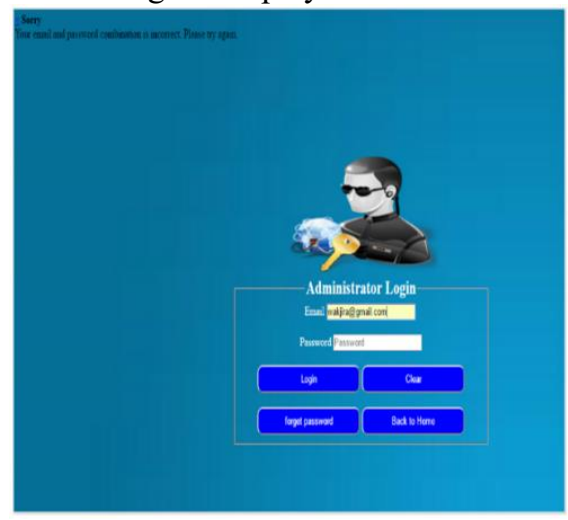

Fig. 21. Login user interface.

\section{B. Validation Testing}

It is a type of testing that the detection system can judge whether the input data is correct or not. Example for creating account

Description if administrator create new account for another user and may be pass one or more text box, enter incorrect data type the website display the validation message.

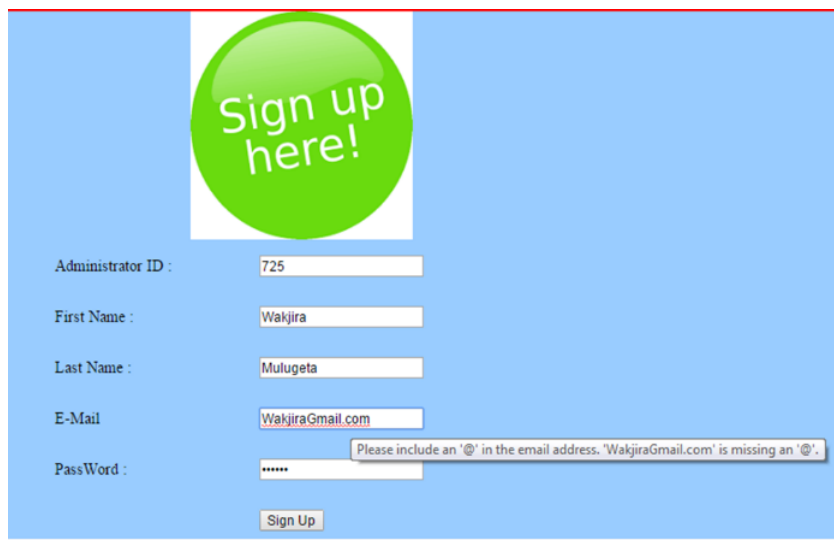

Fig. 22. Create account user interface.

\section{Integration Testing}

Integration testing is show that the integration of one page (form) to the second link form. To test the website correctly integrated. Integrating testing is help to show the link of the first web form to the second web form according to the website activity.

\section{System Testing}

System testing show that all the users in BGRSEB website that had been use the new website.

\section{SySTEM OPERATION AND MAINTENANCE}

The team were developed this website both in good programmable and user interface format. The purpose of this operations and maintenance in this website to insure information about the website is fully functionally and performs optimally until the website reaches its end of life. For operation and maintenance of website this work places the way how to operate and maintain the website in the following.

- If the server(SQL)fail and some data may be loss from the website,first check your pc problem and recovery the website.

- If the website may befail in unknown case report the problem of the website designer fix the problem.

\section{Evaluation}

To meet the objective of this research project the website can be evaluated in such a way that ensured the website is perfectly achieved the objective. In the former time there is no website for the Benishangul Gumuz regional state of educational bureau, but the proposed website that is designed for the bureau of education its own system.

Evaluation can be applied to various purposes and specific activities, projects or plans. Evaluation research is more comprehensive in nature, covering all aspects of the project, 
while the information provided by monitoring is mainly to evaluate and help maintain or accelerate the improvement of achievements. The system can be evaluated by attaining the following conditions:

$>$ Comparing with the current system, Accessibility of information, Readability and accuracy of information and Timeliness of information distribution.

$>$ Checking its user friendly.

$>$ Examining the system for effectiveness and efficiency.

Based on the efficiency of this research project, the time saved and memory space are evaluated, and the effectiveness of this project is evaluated.

\section{RESULT AND DISCUSSION}

\section{A. Result}

The expected Result of this research project is that of functional, effective, and attractive website which promote the education sector well and supply advertisement. The system would easily be able to save files and the user can access from the user interface. Regarding this, it should be updating, deleting, registering, searching, retrieving and accessing dynamically files from the database desk. The actors exist in this system are Administrator and User.

\section{B. Discussion}

In the researchers conversation that are decided how this system is applied and improved the benishangul gumuz regional state of Ethiopia educational bureau sector hitches owing to the development of the website and either what the assessors or the compliance are observed and inspected or examined.

\section{CONCLUSION}

Working things manually is become problematic due to this educational sector takes great role in developing website. That is why we stand for designing website for the Benishangul Gumuz regional state of Educational bureau. The sector office doesn't have its own website, it provide services for the customers manually. It also does not longdrawn-out relation with other sectors that exists in the region. Meaning that the design of website for the BGRS educational bureau introduce the region very well, providing easy and fast service to the users.

In general the website is placated any visitor to bounce debauched service. Availability of data for security mechanism to gratify employee to lessen their work load. In this study, users can easily access information and the employee can provide information on the updated website.

The team recommends that the Benishangul Gumuz regional state of educational bureau is still used completely manual system to accomplish any goings-on and functions so the sector office should use the website to enhance and develop the bureau of education sector of the region more active. Organizations have to trace their consideration on consuming the latest technology to be the best and modest. For such consequences organizations able to use information technology to effectively succeed their objective. From the different particulars that launch the project, the following recommendations are suggested:

$>$ Thoughtful attention should have to be assumed in order to develop website for the sector.

$>$ The findings of progressing this research project should include some tools and features: such as Google map, embed YouTube videos, social network public page, Google powered language translation, Google search and other advanced programming tools and features.

\section{ACKNOWLEDGMENT}

First,I would like to express my grateful thanks and gratefulness to my advisor. And also I would like to express gratefulness and appreciation to my department staff members for their valuable advice and guidance. Next,I would like to thank the Benishangul Gumuz Regional sate educational bureau office director Ato Seyum G. and Ato Mitiku Z, and workers of the organizations who gave any information concerning about our research project and their politeness during interviews. Beside this I would like to thanks class mate students .Finally, I would like to thank our parents for their inspirational encouragement and moral support throughout our study of higher institute and all the administration body of Assosa University.

\section{REFERENCES}

[1] B. Wondimu, "An Assessment of School Based Continuous Professional Development (CPD): Practices and Challenges", International Journal of Secondary Education, 2020.

[2] J.Young, "Along Ethiopia's Western Frontier: Gambella and Benishangul in Transition”, Journal of Modern African Studies, 16 march 1999.

[3] S. S. Zarish, Sh. Habib, M. Islam, "Analyzing Usability of Educational Websites Using Automated Tools," IEEE 019 International Conference on Computer and Information Sciences (ICCIS), 2019.

[4] P. Jogoo, I. Sh. Golamgous, Y. Chuttur, "From Desktop to Mobile View: A Simplified Approach to Mobile Website Development," IEEE 2019 Conference on Next Generation Computing Applications (NextComp), 2019.

[5] R. Gultom, Y. Nugraha, Hamdi1, H. Wiguna1, H.Terissa, J. I. Kanggrawan, Z. Nursyufa, R. Y. Gusta, Y. Hadi, A. Hirzirahim, A. Ernesto, A. I. Satria, M. A. Mubarok, A. L. Suherman, "Developing the government COVID-19 website: Lessons Learned from Jakarta,' IEEE, 2020.

[6] A. Smith, L. Dunckley, T. French,Sh. Minocha, Y. Chang, "Reprint of a process model for developing usable cross-cultural websites," IEEE, vol. 24 , no. 4, July 2012.

[7] S. E. Ullah, T. Alauddin, H. U. Zaman, "Developing an E-commerce website," IEEE2016 International Conference on Microelectronics, Computing and Communications (MicroCom), 2016.

[8] J. Shi, Y. Cao, X. Zhao, "Research on SEO strategies of university journal websites," IEEE The 2nd International Conference on Information Science and Engineering, 2011.

[9] S. J.hong, L. J.Sheng, S. Yanling, "Comparative research of developing technologies of website," IEEE 2009 International Conference on Future BioMedical Information Engineering (FBIE), 2010.

[10] J. H. S. Yin, K. Chew, N. Khan, "Humanizing websites: Website personality for E-services," 2015 IEEE International Conference on Industrial Engineering and Engineering Management (IEEM), 2016.

[11] Ch. Liu, "Developing Measures and Prioritizing Digital Capital of Real Estate Websites," IEEE2009 WRI World Congress on Computer Science and Information Engineering, 2009.

[12] N. Verma, J. Singh, "Improved Web Mining for E-commerce Website Restructuring," IEEE 2015 IEEE International Conference on Computational Intelligence \& Communication Technology, pp. 155 160, 2015

[13] F. Sh. Effendi, I. Alfina, "Quality evaluation of airline's e-commerce website, a case study of AirAsia and Lion Air websites," IEEE 2014 
International Conference on Advanced Computer Science and Information System, 2015.

[14] H. Shafiee, S. Shafiee, E. Shafiee; F. Mortazavi, "Identify the effective factors on Website Quality in electronic banking," IEEE2015 9th International Conference on e-Commerce in Developing Countries: With focus on e-Business (ECDC), 2015.

[15] A. Nurabadi, I. Bafadal, I.Gunawan, A. S. I. Burham, E. J. Bengen, "Website Development for Principals Induction Program," IEEE 2020 6th International Conference on Education and Technology (ICET), pp. 205-208, 2020.

[16] A. Edmonds, R. W. White, D. Morris, S. M. Drucker, "Instrumenting the Dynamic Web," Journal of Web Engineering (JWE), vol. 6, no. 3, pp. 244-260, September 2007.

[17] Arnd Kohrs; Bernard Merialdo, "Creating user-adapted Websites by the use of collaborative filtering," IEEE, vol. 13, no. 6, 2001.

[18] S. Tilley, K. Wong, "Developing multilingual websites: An experience report from the 24th IEEE international conference on software maintenance in Beijing, China", IEEE, 2013.

[19] P. McFarlane, "Developing a Culturally Specific E-Learning Website," IEEE, 2007.

[20] M. Lee, H. Young Lee, M. Yoon, "Website development strategy for e-Commerce success," IEEE, December 2010.

[21] Sh. Otsuka, K. Kato, V. Klyuev, "Academic laboratory website development," IEEE, 2015.

[22] N. Fil, L. Nefedov, A. Binkovskaya, "A Model for Choosing Hosting for a Company's Website," IEEE, April 2020.

[23] Tibken Shara, "Aereo TV streaming expands to major Web browsers," CNET.CBS Interactive, 17 October, 2012

[24] Warren Tom, "Microsoft relegates Internet Explorer to a 'legacy engine' to make way for new browser," March, 2015.

[25] Wayner Peter, "Battle of the Web browsers," 27 April 2011.

[26] Andersen Starr, Abella Vincent, "Part 5: Enhanced Browsing Security," Changes to Functionality in Microsoft Windows XP Service Pack 2, 15 September 2004.

[27] Sh. Bejano, G. Shumie, A. Kumar,E. Asemahagn et al. "Prevalence ofasymptomatic visceral leishmaniasis in human and dog,Benishangul Gumuz regional state, Western Ethiopia," ResearchSquare, 2020.

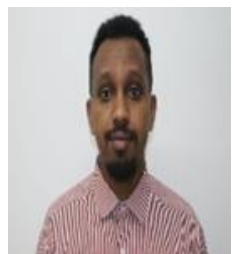

Asefaw Wakjira Mulugeta received the B.S. degree in information science from the School of computing and informatics, Assosa University, Assosa, Ethiopia, in 2017. Now He is pursuing the M.S. degree in School of computer science and technology, Xidian University, Xi'an, China. His research interests include Data mining and Machine learning.

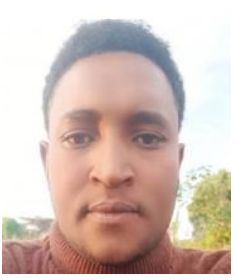

Hambisa Mitiku (Assistant professor) received the B.S. degree in information science from the School of computing and informatics, Haramaya University, Haramaya, Ethiopia, in 2010 and M.S. degree in information science from the School of computing and informatics, Jima University, Jima, Ethiopia, in 2014. Now He is Lecturer in School of computing and informatics, information science department, Jima University, Jima, Ethiopia. His research interests include IKM, health informatics, and Knowledge management. 